\title{
Supply and demand mismatch for flexible (part-time) surgical training in Australasia
}

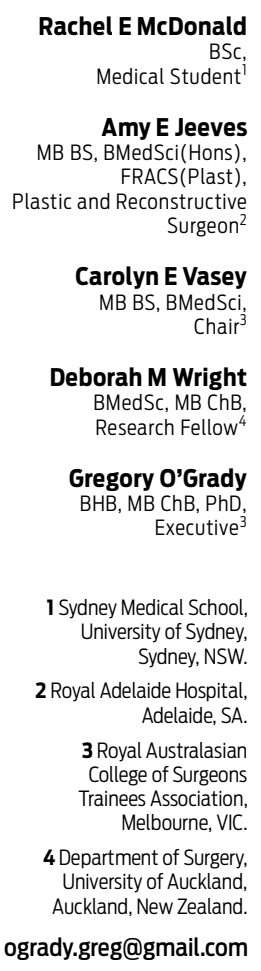

MJA 2013; 198: 423-425 doi: $10.5694 / \mathrm{mjal} 2.11685$

Commentary p 426 urgical training follows an apprenticeship model, traditionally involving long hours of full-time mentored practice over several years. Recently, this model has been challenged by several trends, including working-hour restrictions, falling case exposure, and a desire for work-life balance. ${ }^{1-3}$ Another challenge is an increasing demand for flexible (part-time) training. ${ }^{4,5}$

The Royal Australasian College of Surgeons (RACS) supports flexible training by allowing trainees to accredit part-time work, but it mandates a time commitment of at least $50 \%$ during any training year. ${ }^{6}$ However, the opportunity to train parttime in surgery is also influenced by hospital employers and supervisors, and the supply of part-time surgical training posts is limited.

There are currently no data from our region regarding the number of surgical trainees undertaking flexible training. Our primary aim was therefore to define current flexible surgical training uptake and demand in Australia and New Zealand. A secondary aim was to identify demographic and work-related factors motivating interest in flexible training.

\section{Methods}

All 1191 trainees enrolled in an RACS program during 2010 were identified through the College's database and invited by email to complete an anonymous online questionnaire, with weekly reminders over 4 weeks. Approval was granted by the RACS Ethics Committee.

The survey comprised four sections with option buttons. The first section defined demographic characteristics, including age, sex, specialty and Surgical Education and Training (SET) program year. Demographic data were also analysed to determine

\section{Abstract \\ Objectives: To define current patterns of flexible (part-time) surgical training in Australasia, determine supply and demand for part-time positions, and identify} work-related factors motivating interest in flexible training.

Design, setting and participants: All Royal Australasian College of Surgeons trainees $(n=1191)$ were surveyed in 2010 . Questions assessed demographic characteristics and working patterns, interest in flexible training, work-related fatigue and work-life balance preferences.

Main outcome measures: Interest in part-time training, and work-related factors motivating this interest.

Results: Of the 1191 trainees, 659 responded (response rate, 55.3\%). Respondents were representative of all trainees in terms of specialty and sex. The median age of respondents was 32 years, and 187 (28.4\%) were female. Most of the 659 respondents $(627,95.1 \%)$ were in full-time clinical training; only two $(0.3 \%)$ were in part-time clinical training, and $30(4.6 \%)$ were not in active clinical training. An interest in part-time training was reported by 208 respondents (31.6\%; $54.3 \%$ of women $\vee 25.9 \%$ of men; $P<0.001$ ). Trainees expressing an interest in part-time training were more likely to report that fatigue impaired their performance at work and limited their social or family life, and that they had insufficient time in life for things outside surgical training, including study or research $(P<0.05)$.

Conclusions: There is a striking mismatch between demand for flexible surgical training and the number of trainees currently in part-time training positions in Australia and New Zealand. Efforts are needed to facilitate part-time surgical training.

whether the responding sample was representative of all RACS trainees. The second section defined current working hours, and the third section rated work-related fatigue. Trainees were asked if they worked part-time, full-time or were not currently in active clinical training (ie, interrupted or deferred, such as for research or parenting). Results concerning trainee working hours and impacts of fatigue have been reported elsewhere. ${ }^{3,7}$ The fourth section used Likert scales to ascertain respondents' perceptions of their work-life balance and interest in flexible training. This section included the question, "Are you interested in the option of applying for flexible (less than full time) training during your surgical training?". Responses were assessed for differences between sexes and specialties. Further analyses were undertaken to identify whether interest in flexible training was correlated with working hours or fatigue.
Analyses were performed using SPSS version 19.0 (IBM), using cross tabulations with the $\chi^{2}$ test (threshold $P<0.05)$.

\section{Results}

Of the 1191 trainees, 659 responded (response rate, $55.3 \%$ ), and 587 respondents $(89.1 \%)$ completed all relevant questions. Respondents were similar to all trainees in terms of specialty $(P=0.22)$ and sex $(P=0.09)$. Of the 659 respondents, 187 (28.4\%) were female, with the proportion of women differing between specialties $(P=0.02)$, ranging from $2 / 19$ in cardiothoracic surgery to $9 / 16$ in paediatric surgery (Box 1). The median age of respondents was 32 years (range, 24-50 years).

Most of the 659 respondents (627, $95.1 \%)$ were engaged in full-time clinical training, with 30 (4.6\%) not in active clinical training, and only two 


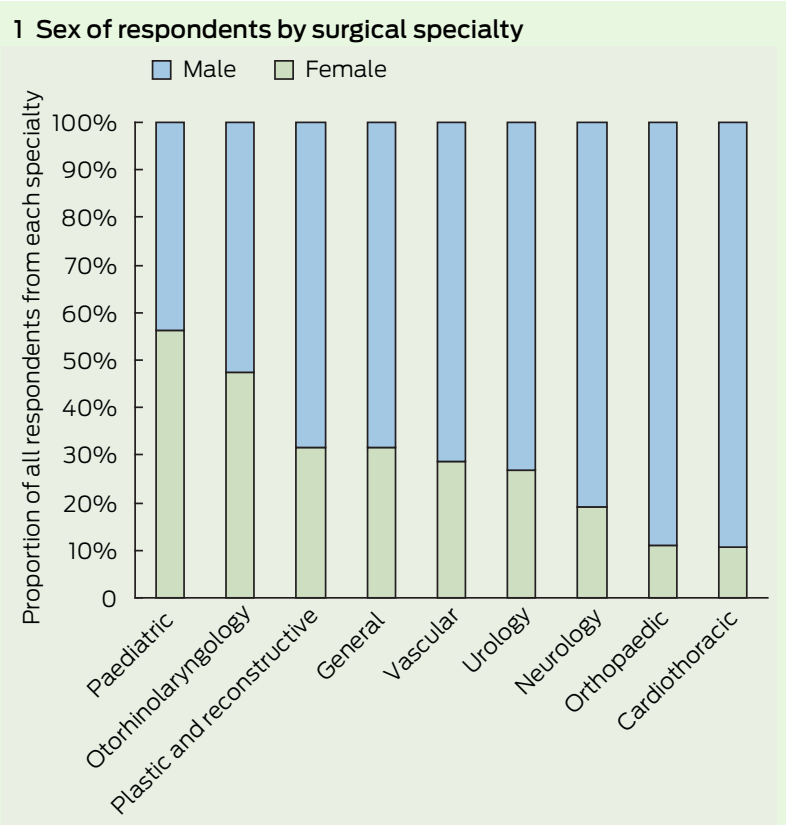

2 Comparisons of male and female trainee responses to questions about interest in flexible training (A) and time outside training for other things $(B)$

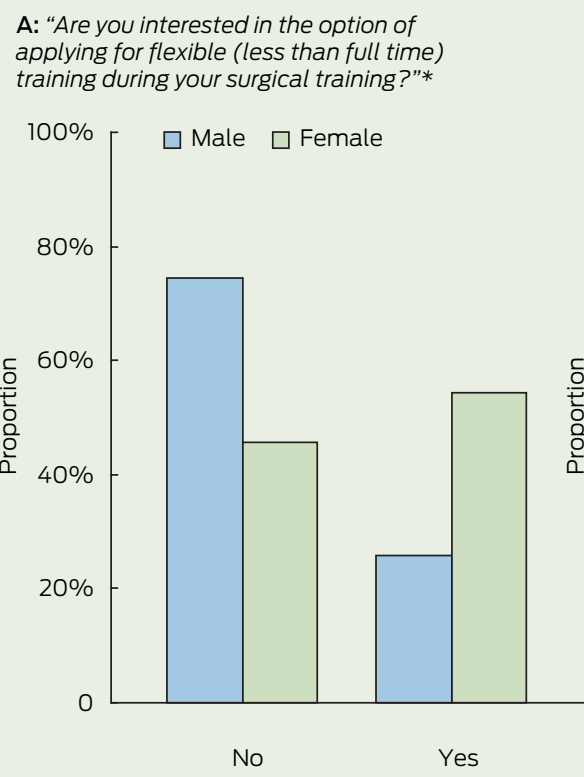

Response
B: "I have satisfactory time in my life for things outside of surgical training"

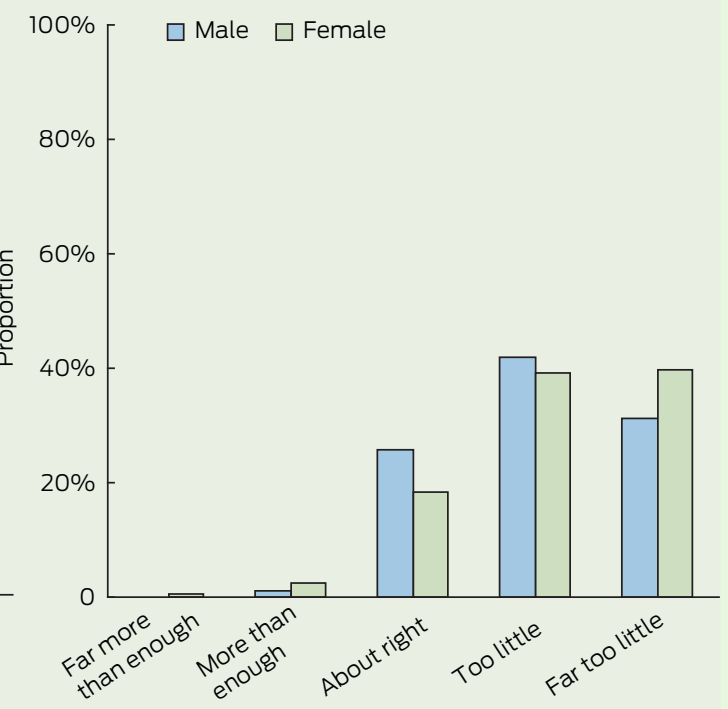

Response

$* P<0.001$ for male $v$ female. $\dagger P=0.06$ for male $v$ female

3 Factors associated with an increased interest in flexible training

Factor

Fatigue is impairing concentration or performance at work

Fatigue is limiting participation in social or family life

Current working hours are in excess of preferred work-life balance

Perceived insufficient time in life for things outside of surgical training

Perceived insufficient time for surgical study and research needs

* Each question was assessed on a five-point Likert scale. $P$ values reflect $\chi^{2}$ analyses of Likert response and interest in flexible training. The full datasets for these analyses are provided as an Appendix (online at mja.com.au). ior trainees were more likely to express an interest than senior trainees $(45.8 \%$ [60/131] and $38.4 \%$ [56/ 146] for SET years 1 and 2, respectively, v $24.8 \%$ [26/105] and $26.4 \%$ (23/87) for SET years 4 and 5-6, respectively; $P=0.002)$. Trainees interested in part-time training were more likely to express concerns regarding fatigue impairing their work performance and limiting their social or family life, inadequate work-life balance, and insufficient time for things outside surgical training, including study or research (Box 3 and Appendix, online at mja.com.au).

General and orthopaedic surgery trainees were most likely to report an interest in flexible training $(41.6 \%$ [116/279] and 32.5\% [37/114], respectively), while cardiothoracic and vascular surgery trainees were least likely (6.7\% [1/15] and 8.0\% [2/25], respectively). Female general surgery trainees were more likely to be interested $(65.2 \%$ [58/89]) than female trainees in other specialties $(P=0.04)$.

There was no significant difference in work-life balance satisfaction between male and female surgical trainees with respect to working $\geqslant 60$ or $<60$ hours per week $(P=0.48)$. About two-thirds of trainees reported currently working "too many" or "far too many" hours in terms of their preferred work-life balance (men, 62.0\% [259/418] and women, 65.1\% [110/169]). Trainees' opinions on whether they had satisfactory time in their lives for things outside of surgical training are shown in Box 2, B.

\section{Discussion}

This study demonstrates a striking mismatch between interest in flexible training among Australasian surgical trainees and the number of trainees currently in a part-time post. Although $32 \%$ of trainees were interested in flexible training, less than $1 \%$ were engaged in part-time clinical training.

These results show a previously undocumented high level of interest in flexible training among both male and female trainees. The rate of interest among men was higher than the $13 \%$ rate reported among male general surgical residents and medical students in 
the United States. ${ }^{4}$ The leading factor known to motivate interest in flexible training is time for parenting, ${ }^{4,8}$ and the mean age of trainees in our study (32 years) coincides with the age when Australians would typically choose to become parents. ${ }^{9}$ Impact on family life has been found to be among the biggest regrets of US surgeons regarding their time in residency, ${ }^{4}$ and the American Surgical Association has previously called for increased flexibility in training to facilitate parenting. ${ }^{5}$ Our results show that similar efforts are required in Australasia. Limited opportunities for flexible training may discourage graduates from considering a surgical career. ${ }^{10-12}$

Our study also found that workrelated factors are associated with interest in flexible training. On average, Australasian surgical trainees work more than 60 hours per week, and around $75 \%$ also perform on-call duties for a further 28 hours per week. ${ }^{7}$ A previous study of Younger Fellows of the RACS showed that those working more than 60 hours per week were at higher risk of "burnout", 13 which could perhaps be mitigated by increased work flexibility. Factors other than family and fatigue, such as health and academic interests, are also likely to contribute to interest in flexible training. ${ }^{4,8,14}$

Barriers to flexible surgical training that may explain the low uptake in our study include clinical, supervisory, trainee and employment factors. ${ }^{12,14,15}$ From a clinical and supervisory perspective, the potential impact of parttime training on continuity of care, and the associated need for additional handovers, is a concern. ${ }^{16}$ As part-time training occurs at a lower intensity and over a longer period, it may also be an impediment to gaining technical skills. ${ }^{15}$ Few educational data are currently available to assess this, but limited Australasian experience suggests quality outcomes can be achieved within the right model. ${ }^{14}$ Factors deterring trainees from flexible training include prolongation of training, a trade-off in salary and benefits, complexities in negotiating a part-time hospital contract, a perception of receiving "second-class training", and discouragement from supervisors and other trainees. ${ }^{4,17}$ In addition, the limited availability of part-time hospital appointments is a key barrier. ${ }^{14}$ It may be difficult in some rotations to provide trainees with the necessary range of clinical experience (spanning acute, elective, operative and non-operative experience) in a flexible capacity.

Despite these challenges, opportunities exist to enhance the supply of flexible surgical training posts. Two possible models are job-sharing and stand-alone posts, both of which have successful precedents in Australia. ${ }^{12,14}$ Job-sharing can be facilitated by allowing trainees to "match" into suitable posts, but this typically must be planned months in advance and may be difficult in smaller specialties or regions. A possible path to advancing flexible training through a stand-alone model is through private hospital rotations, which are a focus of increasing interest in Australasia. ${ }^{18}$ Private sector training imposes opportunity costs on surgeon and hospital income, ${ }^{19}$ which could be partly offset by these positions being part-time, if quality operating exposure could be assured. Jobsharing in acute surgical units offers an opportunity to mitigate impacts on continuity of care, as scheduled handovers occur continuously during the 24-hour acute care model. ${ }^{20,21}$

Female students now outnumber male students in Australasian medical schools, ${ }^{22}$ and our study suggests the proportion of female trainees in surgery is also growing. Although only around $8 \%$ of qualified Australasian surgeons are women, ${ }^{23}$ we found that $28 \%$ of RACS trainees are women, indicating that a workforce transition is occurring. As we also found that more women than men are interested in flexible training, these demographic trends are likely to increase pressure for part-time training opportunities.

A limitation of our study is the sourcing of data from self-survey responses; however, the response rate was satisfactory. ${ }^{24}$ Further, a reported interest in flexible training may not translate into uptake of flexible training, even if the opportunities are available.

In conclusion, we believe efforts should be made to facilitate part-time surgical training in our region.

Competing interests: No relevant disclosures.

Received 18 Nov 2012, accepted 20 Mar 2013.

1 Purcell Jackson G, Tarpley JL. How long does it take to train a surgeon? BMJ 2009; 339: b4260.

2 Curet MJ. Resident work hour restrictions: where are we now? J Am Coll Surg 2008; 207: 767-776.
3 O'Grady G, Harper S, Loveday B, et al. Appropriate working hours for surgical training according to Australasian trainees. ANZ J Surg 2012; 82: 225-229.

4 Saalwachter AR, Freischlag JA, Sawyer RG, Sanfey HA. Part-time training in general surgery: results of a web-based survey. Arch Surg 2006; 141: 977-982.

5 Debas HT, Bass BL, Brennan MF, et al. American Surgical Association Blue Ribbon Committee report on surgical education: 2004. Ann Surg 2005; 241: 1-8.

6 Royal Australasian College of Surgeons Education and Training Administration. Trainee registration and variation policy. Melbourne: RACS, 2011. http:// www.surgeons.org/media/297605/pol_2011-11-07_ trainee_registration_and_variation_policy_v2.pdf (accessed Apr 2012).

7 O'Grady G, Loveday B, Harper S, et al. Working hours and roster structures of surgical trainees in Australia and New Zealand. ANZ J Surg 2010; 80 : 890-895.

8 Kamei RK, Chen HC, Loeser H. Residency is not a race: our ten-year experience with a flexible schedule residency training option. Acad Med 2004; 79: 447-452.

9 Hayes A, Weston R, Ou L, Gray M. Families then and now: 1980-2010. Melbourne: Australian Institute of Family Studies, 2010. http://www.aifs.gov.au/ institute/pubs/factssheets/fs2010conf/fs2010 conf.pdf (accessed Jun 2012).

10 Harris MG, Gavel PH, Young JR. Factors influencing the choice of specialty of Australian medical graduates. Med J Aust 2005; 183: 295-300.

11 Rogers ME, Creed PA, Searle J. Why are junior doctors deterred from choosing a surgical career? Aust Health Rev 2012; 36: 191-196.

12 Tomlinson J, Bollard R, Colville DJ, et al. Flexible surgical training: it is time for change. ANZ J Surg 2012; 82: 866-867.

13 Benson S, Sammour T, Neuhaus SJ, et al. Burnout in Australasian Younger Fellows. ANZ J Surg 2009; 79 : 590-597.

14 Neuhaus S, Igras E, Fosh B, Benson S. Part-time general surgical training in South Australia: its success and future implications (or: pinnacles, pitfalls and lessons for the future). ANZ J Surg 2012; 82: 890-894.

15 Truskett $P$. Is part-time surgical training feasible? ANZ J Surg 2012; 82: 859-860.

16 Fischer JE. Continuity of care: a casualty of the 80 hour work week. Acad Med 2004; 79: 381-383.

17 Abbett SK, Hevelone ND, Breen EM, et al. Interest in and perceived barriers to flexible-track residencies in general surgery: a national survey of residents and program directors. J Surg Educ 2011; 68: 365-371.

18 Royal Australasian College of Surgeons. Surgical workforce projection to 2025. Melbourne: RACS, 2011. http://www.surgeons.org/media/437871/rpt racs_workforce_projection_to_2025.pdf (accessed Jun 2012).

19 Aitken RJ. Lost opportunity cost of surgical training in the Australian private sector. ANZ J Surg 2012; 82: 145-150.

20 Nagpal K, Arora S, Abboudi M, et al. Postoperative handover: problems, pitfalls, and prevention of error. Ann Surg 2010; 252: 171-176.

21 Cox MR, Cook L, Dobson J, et al. Acute Surgical Unit: a new model of care. ANZ J Surg 2010; 80: 419-424.

22 Medical Deans Australia and New Zealand. 2011 medical students statistics. Sydney: MDANZ, 2011. http://www.medicaldeans.org.au/wp-content/ uploads/Table-2-Website-Stats-2011.pdf (accessed Jun 2012).

23 Royal Australasian College of Surgeons. Surgical workforce 2009. Melbourne: RACS, 2009. http:// www.surgeons.org/media/300167/Surgical_ Workforce_2009.pdf (accessed Jun 2012).

24 Asch DA, Jedrziewski MK, Christakis NA. Response rates to mail surveys published in medical journals. JClin Epidemiol 1997; 50:1129-1136. 